\title{
nature
}

\section{Technology transfer requires an entrepreneurial academia}

Attempts to replicate the recent success of US technology transfer need to focus on the toughest elements of the problem: the availability of venture capital and the structure of the university system.

$F^{\mathrm{i}}$ inding the magic formula for the successful transfer of technology from universities and government laboratories to commercial application is a perennial quest of governments around the world. With the United States enjoying an economic boom of unprecedented strength and duration - partly on the back of its success in information technology and, to a lesser extent, biotechnology - interest in the question is all the greater.

This summer, for example, Japan's parliament has passed a law, similar to the Bayh-Dole Act passed in the United States in 1980, that will allow universities and government laboratories to grant exclusive patents to private companies with which they have gone into partnership (see page 3). An influential panel in Canada, meanwhile, is urging the government to strengthen universities' means of protecting and exploiting their intellectual property, and to push the universities to pursue commercial opportunities more aggressively (see Nature 400, 805; 1999).

Various factors have contributed to the US success, and some are easier to replicate than others. A legal framework has been put in place which allows private companies in the United States to gain exclusive patent rights to ideas that were initially developed with public money. An argument can be made that this is unfair to the taxpayer. But experience suggests that only the private sector is ultimately capable of efficient commercial exploitation of such ideas. It follows that, elsewhere as in the United States, public research agencies must accept the need to pass the baton of intellectual-property rights firmly and unconditionally to the private sector.

The availability of venture capital is also critically important, but it is not something that governments can readily legislate for. Venture-capital markets in Europe and elsewhere remain disappointingly small compared with that of the United States, whose diversity of venture-capital sources - including wealthy individuals willing to take a gamble on a good idea - remains unmatched elsewhere.

Perhaps the most impressive element of the US technology-transfer chain, however, is the university system itself. Public and private universities are able to compete freely in an environment in which faculty are highly mobile and strong departments can rapidly emerge - or decline - subject to the quality of their work. The system is always ready to take a chance on talented young faculty, and is itself highly entrepreneurial.

That environment is hard to replicate alongside the statecontrolled higher-education system of other industrialized countries. Most of them have tried to shake things up over the past decade, with conspicuously little success. Powerful interests, most notably senior academics, are deeply entrenched and opposed to change.

A legal structure that allows intellectual property to escape from universities and government laboratories is a necessary but insufficient prerequisite for efficient technology transfer. It is the absence of venture capital and, above all, of a dynamic and flexible university system that is most likely to frustrate those seeking to emulate US strength in technology transfer.

\section{Changing Nature (cont.)}

This issue includes some enhancements to Nature's subliminal impact.

ditors of any publication are well used to the fact that most readers simply want to get the 'story' - the news, the opinion, the new discoveries — whereas the skills that are deployed in writing, editing and visually presenting the story are, by and large, taken for granted. That, of course, is a sign of professional success readers are quick to notice when standards slip, but may not fully appreciate the reasons why an excellent piece of content achieves its impact. Never mind. Informal feedback and the harder measure of climbing circulation suggest that, although they may not appreciate the full reasons for it, the number of people wanting or needing to open Nature's pages every week continues to grow.

Those discreet aspects of content are more noticeable when they are changed, however, and several such developments are marked by this week's issue. Take our design. In January last year we introduced a significant change in our appearance. That redesign has withstood the test of time. Nevertheless, we feel that some slight improvements are desirable, which is why the pages in the front sections in particular now have a lighter feel to them, stemming from changes in typeface, the use of linear design features and the style of page layout.

We have also changed the order of sections. Time was when book reviews were published at the back of the journal. More recently they have been sandwiched between two much more technical sections. The Book Reviews section surely deserves more prominence. It now appears further towards the front.

And finally, we have changed the name of the Scientific Correspondence section to 'Brief Communications'. The primary reason is to avoid confusion with our Correspondence section, which consists of informal communications on non-technical matters. As with Scientific Correspondence, Brief Communications are peer reviewed and scientific in character. Some are responses to papers published in Nature. The majority, however, report self-contained scientific results that are of unusual interest - perhaps for their policy implications, or for their unexpectedness, or even for their sheer entertainment value. Although the advance in fundamental understanding represented by Brief Communications may not typically be as great as in our Articles and Letters, the standards of peer review that we apply to their technical quality are no less strict, while the interest aroused will typically span a broad range across the many disciplines of our readership.

Further changes are in the pipeline. Meanwhile, we hope readers' enjoyment of Nature will be at least subliminally enhanced. 